\title{
Direito e teoria social: três problemas*
}

Gunther Teubner

Tradução do alemão de Patrícia da Silva Santos

A relação entre direito e teoria social tem me ocupado desde que escrevi minha tese de doutorado, ou seja, nos últimos quarenta anos. A seguir, resumo minha experiência:

- Não há uma única teoria social na qual o direito poderia orientar-se. Tal teoria não pode nem deve existir.

- Ao longo dos últimos oitenta anos, o direito alemão sucumbiu em três ocasiões à tentação de submeter-se totalmente a uma teoria da sociedade. Isso levou a dois desastres da teoria. Se o terceiro desastre também influenciará o direito, é uma questão que permanece em aberto.

- O direito está diante de um dilema. É impossível que ele aceite totalmente uma teoria social, mesmo que necessite ser exposto à influência de teorias sociais. A saída poderia ser uma "abordagem distanciada”, segundo a qual o direito não toma as teorias sociais em seu valor nominal, mas, por meio de um complexo processo de tradução, gera “valor agregado” à doutrina jurídica. Verba docente, exempla trabunt. Comecemos, então, com um caso jurídico.

Viés de publicação: um caso jurídico e três teses

Viés de publicação - este é um fenômeno preocupante, mas generalizado, que vem sendo discutido em certo número de países (Song, Hooper e Loke,
* Texto publicado anteriormente em edição bilíngue (inglês e alemão): "Recht und Sozialtheorie: Drei Probleme" - "Law and social theory: three problems", em Ancilla Juris, 2014, pp. 183-222 (tradução para o inglês de Alison Lewis). 
1. Um exemplo: no final da década de 1980, o grupo farmacêutico Sandoz encomendou a um grupo de trabalho da Universidade do Tennessee, em Memphis, a realização do estudo MIDAS, que deveria comparar um novo bloqueador do canal de cálcio com medicamentos mais antigos $\mathrm{e}$ mais baratos. Quando os resultados revelaram que o novo medicamento não oferecia benefícios em comparaçāo com ingredientes testados e aprovados, e, de fato, indicava muitos efeitos colaterais nocivos, a Sandoz tentou impedir a publicação dos dados do estudo, pressionando a equipe de pesquisa (Applegate, Furberg, Grimm e Byington, 1996, pp. 297-298).

2. Um pesquisador da Universidade da Califórnia, em Irvine, recebeu um prêmio de pesquisa da Boots Pharmaceuticals e se comprometeu a não tornar público quaisquer resultados potencialmente negativos sem o aval do grupo. Com base na cláusula contratual de censura, a publicação foi impedida durante um período de anos. Uma ação judicial foi movida contra o grupo por supressão de dados, propaganda desonesta e violação de regulações de consumo (King, 1996).

3. Em 1997, Pfizer publicou apenas uma pequena parte dos estudos efetivamente realizados com seu medicamento antidepressivo - especificamente os resultados positivos, enquanto os dados relativos a potenciais efeitos colaterais e a eficácia do ingrediente foram retidos (Eyding et al., 2010).

4. Sobre a execução de registros do governo, ver o decreto vo (EG) 726/2004. A diretriz da Uniāo Europeia EU-RL 2001/20/ EG (implementada em 12. AMG alteração, BGBl., 2004 I, 2013) estabelece para as experiências clínicas uma avaliação simultânea por comitês de ética.
2013; Song, Parekh e Hooper, 2010, pp. 1-220; Schott et al. 2010). Para desenvolver um medicamento eficaz contra uma doença grave, mas rara, diversas instituições públicas e privadas se unem formando uma rede de parceria público-privada (PPP) com base em acordos bilaterais entre eles. Uma vez que os altos custos tornam tais projetos não rentáveis para a indústria farmacêutica, o financiamento provém principalmente de uma fundação privada, e os subsídios são pagos pelo ministério da saúde nacional. Uma instituição universitária compromete-se com a pesquisa básica, enquanto os estudos clínicos são realizados por uma instituição de pesquisa privada (uma organização de pesquisa contratual). Uma empresa farmacêutica privada organiza a produção e a comercialização do medicamento. Uma agência de comunicação cuida da divulgação de informações e publicação de resultados em revistas científicas e outras mídias.

Depois do licenciamento bem-sucedido com base nos estudos clínicos apresentados, o medicamento chega ao mercado. No entanto, depois de um tempo, começam a aparecer frequentes notificações de graves efeitos colaterais em muitos pacientes. A pesquisa sistemática subsequente mostra que a rede de PPP foi responsável por uma grave manipulação. Os efeitos colaterais eram bem conhecidos dentro da rede, mas ela impediu, com êxito, publicações preventivas de resultados relevantes. A publicação de experiências nas quais as consequências negativas apareciam foi omitida ${ }^{1}$. Isso foi de fato autorizado por acordos bilaterais entre as instituições de pesquisa e a empresa farmacêutica ${ }^{2}$. Outras séries de experimentos foram publicadas, mas seus resultados foram falsificados em favor de efeitos positivos ${ }^{3}$. Não apenas a empresa farmacêutica se envolveu na manipulação, mas também os grupos de pesquisadores e a agência de comunicação, que tinham seu próprio interesse em fornecer uma apresentação falsificada dos resultados.

Os inúmeros escândalos ao redor do viés de publicação certamente deram origem a reações fortes. Estudos empíricos mostram que este é um problema onipresente. Tentativas iniciais estão sendo feitas para tomar contramedidas regulamentares ${ }^{4}$. No entanto, os problemas que surgem aqui não são simplesmente problemas de controle político, mas também questões fundamentais relacionadas com o direito constitucional: será que o direito fundamental de liberdade acadêmica também possui eficácia horizontal contra terceiros (Drittwirkung) dentro de redes de PPP semiprivadas? O direito fundamental dos pacientes à saúde pode ser afirmado em face da rede ou de seus membros individuais?

A questão de se e como os direitos fundamentais podem reivindicar validade em face de redes privadas também é de grande interesse para a teoria social. 
As teorias da "sociedade em rede", como a que desenvolveu, por exemplo, Manuel Castells, veem as redes de atores coletivos por toda a sociedade como a característica distintiva de sociedades pós-modernas e identificam as "falhas na rede" como riscos sociais graves (Castells, 2000; Weyer, 2011). As formas de direitos fundamentais estão sendo ameaçadas de extinção nas esferas não governamentais, em mercados, organizações e redes. Não é apenas uma questão que diz respeito a juristas, mas também uma questão levantada por várias teorias sociais, por exemplo, a sociologia constitucional de Chris Thornhill; este é um fenômeno atribuído a tendências expansionistas de atores coletivos não governamentais (Thornhill, 2013).

Uma vez que ambos os campos são, juridicamente, "territórios virgens", as conclusões das teorias sociais podem bem ser de grande relevância para o direito. No entanto, se estamos buscando conclusões específicas no que diz respeito à prática jurídica, defrontamo-nos com alguns problemas espinhosos:

- A concorrência entre as teorias: como o direito deve fazer uma seleção se as teorias sociais concorrentes conduzem a análises de rede incompatíveis entre si, ou simplesmente não concordam sobre a validade e o efeito dos direitos fundamentais em face de atores coletivos não governamentais? Sobre esse ponto, a minha tese geral em uma única palavra é: transversalidade.

- Transferência de conhecimento: os resultados das teorias sociais podem ser aplicados diretamente ao direito, ou seja, podem ser implementados padrões de direitos fundamentais adequados às redes? E teorias sociais podem orientar a seleção de sanções contra violações dos direitos fundamentais para que eles possam ser eficazes diante da lógica própria das redes? Mais uma vez, a minha tese pode ser expressa em uma única palavra: responsividade.

- Por fim, há a questão extremamente difícil da normatividade das teorias sociais: critérios normativos para os direitos fundamentais em redes mistas público-privadas podem ser derivados de teorias sociais? Minha tese: a autonormatividade.

Tese 1: transversalidade

\section{As particularidades da história alemã}

$\mathrm{Na}$ Alemanha, a relação entre teoria social e direito experimentou altos e baixos de um modo tão extremo como não foi observado em nenhum outro lugar. Começou em nível europeu geral, com os períodos em que a jurispru- 
5. As contribuições sociológicas mais importantes para a teoria social são, provavelmente, as teorias de diferenciação social desenvolvidas por Émile Durkheim, Georg Simmel, Max Weber, Talcott Parsons, Pierre Bourdieu e Niklas Luhmann. Um resumo pode ser encontrado em Schimank (1996). O direito e a doutrina jurídica em si também são abrangidos por esse processo de autonomização (sobre esse ponto, ver a seção "Tese 2: responsividade", adiante), com a consequência de que o positivismo legal está se tornando predominante. dência existia em relação simbiótica estreita com as teorias acerca de como os seres humanos vivem juntos. Essa constatação se aplica não só às cosmologias do direito natural, mas também ao período do Iluminismo, quando a filosofia reivindicou, de maneira audaciosa, o desenvolvimento de uma teoria da sociedade que deveria estabelecer princípios obrigatórios em matéria de política e direito. $\mathrm{O}$ direito racional expressa essa relação simbiótica, na qual, de acordo com Franz Wieacker, a antiga filosofia ocidental do direito e da sociedade ("direito natural") - na forma a ela concedida no início do Iluminismo - adquiriu influência direta sobre a jurisprudência, a legislação e a administração da justiça na maioria das nações europeias (Wieacker, 1996, \$15 I). Esse desenvolvimento atingiu seu ponto alto nos países de língua alemã, quando Carl von Savigny respondeu à teoria social de Immanuel Kant, formulada como uma sociedade de indivíduos, com o sistema moderno do direito romano: “Todo direito existe por causa da liberdade moral inerente a cada ser humano individual" (Savigny, 1840, p. 2). A teoria social kantiana, que sustenta que os cidadãos têm esferas de liberdade de escolha delimitadas umas das outras de maneira ideal, de tal modo que o direito pode assumir uma forma que é capaz de generalização, foi traduzida para uma doutrina jurídica que via a si mesma como um sistema abrangente de direitos subjetivos.

Logo, porém, a filosofia teve que desistir de seu papel como a "ciência guia" para o direito. Devido à aceleração da diferenciação funcional da sociedade, diferentes esferas de racionalidade tomaram, cada uma, sua própria existência separada, de modo que não foi mais possível assegurar um único ponto de vista ordenador a partir do qual pudesse ser desenvolvido um conceito jurídico unificado da sociedade 5 . Na sociedade de hoje, "sem qualquer vértice ou centro”, como descreve Niklas Luhmann (1990, p. 43), é, em princípio, impossível conceber qualquer teoria social genericamente válida para que o direito possa ser incorporado. "O próprio sistema da sociedade torna-se tão complexo sob tais condições que não permite mais ser compreendido por uma única descrição do sistema” (Luhmann, 1992b, p. 156). Em vez disso, com base em diferentes racionalidades sociais, uma multiplicidade de teorias sociais independentes é desenvolvida - elas são totalmente diferentes, mais ainda entrelaçadas e dependentes umas das outras. Essa situação nem mesmo dá origem a uma controvérsia "normal" de teorias que pudesse ser, ao final, decidida em favor de uma teoria qualquer mais plausível. Pelo contrário, surge um tipo inteiramente novo de situação, para o qual o filósofo Gotthard Günther deu o nome de "policontexturalidade" (Günther, 1976). Em sua racionalidade própria específica, diferentes "mundos de sentido" sociais criam 
suas próprias teorias isoladas da sociedade, que já não podem ser reduzidas a uma única teoria padrão, mas existem lado a lado com base em origens iguais. Max Weber já tinha falado em um "novo politeísmo” em uma situação histórica que torna impossível qualquer "monoteísmo" de teorias (Weber, 1968, p. 605 e ss.; Schluchter, 1988, p. 302). Não há mais uma teoria da sociedade, mas apenas teorias de campos parciais igualmente justificadas. No entanto, cada uma delas - e isso é o que causa preocupação - reivindica, ao mesmo tempo, validade universal como a única teoria da sociedade. Este é o paradoxo - uma multiplicidade de racionalidades parciais com reivindicações totalitárias - que o direito deve enfrentar hoje, se almeja obter uma orientação das teorias sociais ${ }^{6}$.

As teorias econômicas ultrapassaram, há muito, os limites de seu verdadeiro tema - a economia - e pretendem fornecer uma teoria de todas as relações sociais, que compreende a sociedade - e, portanto, também o direito - como uma vasta rede de cálculos de utilidade. A eficiência torna-se um princípio do direito (Eidenmüller, 1995). De forma semelhante, as teorias políticas percebem a sociedade como poder e conflitos de interesse entre grupos e associações políticas e pretendem representar uma "ciência guia" obrigatória para ela e para o direito 7 . O fundamento democrático-consensual como o núcleo da racionalidade política reivindica ser implementado em todo o direito. Por sua vez, as teorias sociológicas de papéis sociais, que foram desenvolvidos para o nível micrológico da sociedade, são extrapoladas para o nível macro, alçando a reciprocidade de papéis sociais ao status de uma norma social geral (Dahrendorf, 1958; Mead, 1967). Mais uma vez, critérios morais tomam tipicamente a forma de interações específicas como prova de apreço mútuo. E, ainda, as teorias sociais da filosofia moral reivindicam a soberania regulamentadora sobre questões e demandas sociais (hoje em dia, principalmente a ecológica) a serem implementadas na forma de normas jurídicas ${ }^{8}$. Por fim, teorias sociais também são desenvolvidas no próprio sistema científico, por exemplo, no racionalismo crítico. Tais teorias insistem em buscar imparcialmente a verdade como o núcleo da racionalidade científica e limitam teorias sociais a diagnósticos e prognósticos. Apesar disso, elas reivindicam uma "cientificização" completa do direito em um processo de "universalização tecnocrática" (Albert, 1993).

No "laboratório Weimar", onde a perda de uma orientação social geral foi avistada no direito, a pluralização de teorias sociais e do direito atingiu o seu ponto alto. Confrontada com a aceleração do pluralismo das teorias sociais sociologia, economia, ciências políticas e filosofia moral - a jurisprudência alemã embarcou em algumas experiências ousadas. As grandes controvérsias a respeito das teorias constitucionais (Carl Schmitt, Hans Kelsen, Hermann Heller), a
6. Sobre as diferentes reivindicações de racionalidade, ver, em maior detalhe, Teubner (1997, pp. 149-176).

7. Um resumo informativo sobre o tema pode ser encontrado em Brodocz e Schaal (2009).

8. O praeceptor Germaniae postbellicae sabe como responder a quase qualquer questão jurídica com a autoridade da teoria social (Habermas, 1996).

novembro 2015 
9. Em relação a estes desenvolvimentos do direito privado no século xx, ver Wieacker (1996, $\$ 28$ e ss.), Stolleis e Dunlap (2004, pp. 45 e ss. - doutrina do direito constitucional e da constituição-, pp. 139 e ss. - disputa sobre método em Weimar -, pp. 188 e ss. - diferenciação do direito administrativo).

10. Para uma crítica incisiva em relação a esse ponto, ver Wiethölter (1968, p. 39 e ss.). disputa ao redor da constituição econômica alternativa ou da democracia econômica (Franz Böhm e Hugo Sinzheimer), a invenção da sociologia jurídica, do "direito livre" e da "jurisprudência de interesses" e as abordagens concorrentes da jurisprudência sociológica, do "ponto de vista econômico" no direito, e da “justiça política” são expressões desse pluralismo. Em particular, é a aquisição de um status independente por áreas autônomas do direito (especialmente o direito econômico, o direito social e o direito do trabalho) que testemunha a enorme influência que a pluralização das teorias sociais teve sobre a pluralização do próprio direito?

No entanto, o direito alemão abandonou abruptamente esse pluralismo da teoria social e do próprio direito quando, sob grande pressão da esfera política, sujeitou-se às reivindicações de monopólio de uma Weltanschauung [visão de mundo] única. Durante os pontos baixos da história mais recente do direito alemão, as teorias sociais totalitárias foram bem-sucedidas na imposição de suas regras normativas sobre o direito, sempre que essas regras foram, ao mesmo tempo, suportadas pelo sistema político. No século Xx, o direito alemão sucumbiu mais de uma vez à tentação de submeter-se a tal "imperialismo" de uma teoria social, baseando não só seus princípios fundamentais, mas até mesmo as regras individuais, nos requisitos de uma teoria política guia dominante na época.

A teoria racial do nacional-socialismo foi o primeiro e também o ponto terrivelmente mais baixo em termos de domínio de uma teoria política sobre o direito (Rüthers, 2004). Depois de sua catástrofe em 1945, a relação do direito com as teorias sociais na Alemanha conduziu à direção de duas posições opostas e extremas. No leste, sob enorme pressão política, outra teoria social totalitária - o materialismo dialético - assumiu o controle do direito e do Estado, com consequências fatais para o Estado de direito (Stolleis, 2009, pp. 43 e ss.). O Oeste, pelo contrário, respondeu às indizíveis simbioses entre teoria/direito do fascismo e do socialismo real com um extremo diferente: uma espécie de "reação imunológica" do direito contra qualquer invasão pelo "bacilo" da teoria social ${ }^{10}$. Tendo se tornado, presumivelmente, mais sábia após essa experiência divisória, a doutrina jurídica na República Federal, que se considera autônoma, lutou rigorosamente contra todas as influências estrangeiras da teoria social. Esta defesa autoimposta contra qualquer tipo de interdisciplinaridade permaneceu inabalável até mesmo durante os breves ataques da teoria social, ainda fervorosos, ocorridos em 1968; de fato, o fenômeno da "sociologia diante dos portões da jurisprudência", que era temido por ser uma reversão para o totalitarismo, aumentou ainda mais a tendência para a “autoimunização" da doutrina jurídica (Lautmann, 1971). Em 
termos comparativos, é espantoso como o direito abriu-se extensivamente para as ciências sociais em outros sistemas jurídicos, em especial no direito anglo-saxão. Para os observadores estrangeiros é muito estranho registrar como a jurisprudência alemã - que por causa de sua forte orientação teórica gozou de respeito internacional no século XIX e começo do século XX - passou a estreitar deliberadamente seu foco para a mera doutrina ${ }^{11}$. É irônico que o direito alemão no período do pós-guerra, em seu estado de profunda incerteza, tenha seguido muitas influências internacionais, com uma especial preferência para o mundo jurídico norte-americano, mas resolutamente tenha se afastado dos numerosos movimentos do "direito e..." que predominaram nos Estados Unidos.

No entanto, houve uma exceção. Por volta dos anos de 1970 e 1980, uma teoria social com pretensões de representação exclusiva, que já havia, há algum tempo, dominado todas as áreas do direito como uma "ciência guia" nos Estados Unidos, desfrutando de apoio político enorme e um fluxo abundante de financiamento privado, entrou em cena também na Alemanha (Teles, 2008). A teoria dos custos de transação, a teoria dos direitos de propriedade, as teorias da escolha pública e da análise econômica do direito são vários movimentos na teoria econômica que visam a substituir o conceito desgastado de justiça pelo de eficiência econômica do direito ${ }^{12}$. Esses movimentos reivindicam a inteira substituição da orientação anterior do direito na filosofia moral, não tolerando quaisquer outras teorias sociais. Com autoconfiança e de modo aberto, eles professam uma espécie de "imperialismo da teoria”, permitindo a interdisciplinaridade (por exemplo, na economia institucional), mas apenas em seus próprios termos. No entanto, depois que as teorias econômicas, durante um período de trinta anos, obtiveram uma expansão maciça em todas as áreas da vida, desde o direito, e passando pelas análises econômicas das relações amorosas e da fé religiosa ${ }^{13}$, ocorreu - na crise financeira de 2008 - a terceira catástrofe da teoria, sob os efeitos da qual o monopólio da interpretação econômica em muitas disciplinas entrou em colapso ${ }^{14}$. No entanto, a questão de saber se essa catástrofe também marca o fim do imperialismo do pensamento econômico no direito permanece indefinida.

\section{A abordagem distanciada}

O que se deve recomendar ao direito em sua relação com a teoria social depois de tais mudanças abruptas entre altos e baixos? - Uma abordagem distanciada. É claro que, à luz dessas catástrofes da teoria, a autoimunização a que se dedicou a doutrina jurídica alemã após a guerra parece ser quase a única
11. "Antes, juristas alemães escreviam tratados curtos, mas profundos, como os de Puchta e Windscheid, que tentavam explicar os princípios fundamentais do direito privado. Agora, muitos acadêmicos alemães escrevem contribuições para longos tratados de vários volumes; cada volume é dividido em uma infinidade de subseçōes e cada assunto é escrito por um autor diferente. [...] Die Einheit der Rechtsordnung [A unidade da ordem jurídica] ou deixou de cuidar de si mesma ou é tratada por meio de referências cruzadas" (Gordley, 2008, p. 222).

12. Uma breve apresentação da economia jurídica pode ser encontrada em Butler (2011). É certo que as economias jurídicas até agora não conseguiram uma mesma posição de domínio sobre o pensamento jurídico na Alemanha como elas o têm nos Estados Unidos. Uma provável razão para isso são as tendências de autoimunização da doutrina a que nos referimos anteriormente.

13. Aqui, Gary Becker é especialmente radical (Pies e Leschke, 1998); para uma avaliação positiva, ver Lazear, 2000, p. 99 e ss.

14. Este colapso ocorre mesmo no direito corporativo dos Estados Unidos (Orts, 2013). 
15. Ponto particularmente enfatizado por Wiethölter, para quem o direito apenas estará à altura da época se tiver processado completamente as mensagens da sociologia dos sistemas, da teoria crítica e do institucionalismo econômico (Wiethölter, 1995, p. 89, 95 e ss.; Wielsch, 2009, p. 67 e ss.). opção. No entanto, existe uma alternativa possível: a transversalidade. Em filosofia, a transversalidade foi desenvolvida como uma reação a uma situação semelhante, como um processo para lidar com a pluralidade de discursos pós-modernos que se seguiu ao colapso dos grands récits (ver, em especial, Welsch, 1966). Transversalidade no direito significa: o direito reconhece que, sob extrema diferenciação da sociedade, não há mais uma justificativa para a existência de qualquer teoria social única universalmente válida, mas apenas para uma multiplicidade de teorias de áreas sociais que são iguais em termos de suas origens. Essas teorias derivam a sua justificação de sua convivência, ou seja, do alto nível de autonomia e, simultaneamente, das interdependências recíprocas de diferentes racionalidades sociais. $\mathrm{O}$ direito recusaria, então, não só sua "economicização" unilateral, mas também sua "politização", "sociologização", "cientificização" e "moralização" unilaterais. Defender-se-ia de qualquer pretensão de totalidade de qualquer teoria; no entanto, aceitaria a legalidade própria de teorias sociais coexistindo de maneira justaposta. Ele transformaria - e aqui jaz o desafio atual - a nova pluralidade de jogos de linguagem na formação de conceitos legais e na formulação de normas legais. Isso é possível se o direito insiste na parcialidade das várias teorias sociais e, ao mesmo tempo, apenas se abre para sua influência quando elas postulam afirmações que são válidas para seus campos de atuação.

No entanto, a transversalidade significa mais do que apenas reconhecer a autonomia territorial das teorias associadas a diferentes esferas sociais. Ao entrelaçamento de todos os campos sociais parciais que acompanha a autonomia elevada, o direito deve responder com uma abertura sistemática para a lógica interna de todas as teorias de campos parciais concorrentes ${ }^{15}$. Max Weber antecipou essa transversalidade quando falou de uma "cadeia de decisões finais", que é inevitável no novo politeísmo. Tais decisões devem ser tomadas de maneira situacional e repetidamente quando passamos por meio de reivindicações de diferentes racionalidades (Weber, 1968, p. 507 e ss.; Schluchter, 1988, p. 339 e ss.). Isso não seria uma "seleção" arbitrária qualquer, mas uma obrigação autoimposta de examinar cuidadosamente as reivindicações de todas as teorias para fazer justiça à pluralidade de racionalidades sociais.

A razão transversal no direito rejeitaria categoricamente a pretensão de totalidade afirmada atualmente pelas teorias econômicas; ao mesmo tempo, as reconheceria como autodescrições do sistema econômico. A autonomia e a simultânea interligação de muitas teorias sociais parciais seriam adequadamente consideradas se a relevância primária da expertise econômica fosse reconhecida no direito econômico, o que, contudo, poderia, ao mesmo tempo, significar 
que dentro do direito econômico outras teorias sociais são, pois, juridicamente relevantes em um sentido secundário ${ }^{16}$. Um princípio similar aplica-se em relação a teorias políticas do direito, assim como na teoria da justiça de John Rawls, que pode reivindicar validade primária (mas não exclusiva) apenas no que diz respeito ao campo da constituição política, ou à teoria do discurso de Habermas, que reclamou para si o status de uma teoria social, mas deve ser demovida para o status de uma teoria moral da interação, e só naquele contexto pode aspirar à racionalidade discursiva. Mesmo a teoria dos sistemas (com a qual, em especial, simpatizo-me) não pode reivindicar para si tornar-se uma nova "superteoria" e, assim, uma ciência guia para o direito, visto que é, por sua vez, apenas uma teoria parcial da comunicação social, suas diferenciações e suas interdependências - uma especialista do geral, por assim dizer - que não expressa preferências por quaisquer das racionalidades parciais da idade moderna e seguramente não desenvolve quaisquer dessas racionalidades com uma pretensão de representação única, mas, em vez disso, toma como tema central a validade igualitária de diferentes racionalidades sociais.

Voltemos ao tema do "viés de publicação". O que significa transversalidade para a classificação jurídica de uma rede público-privada na qual empresas farmacêuticas, instituições acadêmicas e órgãos públicos cooperam para desenvolver um novo medicamento? O ponto de partida é o de que um tipo novo de fenômeno como uma rede de PPP não pode ser satisfatoriamente compreendido nem pelo direito contratual nem pelo direito societário. Nem o conceito jurídico de finalidade do contrato nem o de finalidade social (da empresa) fazem justiça aos objetivos de uma rede de diferentes instituições. Pelo contrário, conforme a concordância de muitos autores, um conceito legal separado deve ser desenvolvido, aquele de "finalidade da rede" ${ }^{17}$. Aqui, o direito abre-se prontamente às análises da teoria econômica dos custos de transação, de acordo com as quais atores racionais escolhem a forma nova de uma rede empresarial quando ela oferece vantagens em termos de custos de transação em comparação com as estruturas do direito contratual ou societário (Gómez, 2011,pp. 21, 22, 25; Williamson, 1985, pp. 180 e ss.). Mas quando a teoria econômica vai além e insiste que a finalidade da rede é exclusivamente minimizar os custos de transação, e se, além disso, tenta entregar a regulação do conflito principalmente para a governança privada da rede, rejeitando qualquer intervenção do direito de Estado em razão da ineficiência (Williamson, 1991, p. 273 e ss.), o direito deve opor-se ao monopólio interpretativo econômico. Somente na análise transversal de outras teorias sociais torna-se claro que o novo conceito legal de finalidade da rede cobre uma área de complexidade
16. Um estudo exemplar é oferecido em Wielsch (2008). Em relação ao direito da propriedade intelectual na internet, Wielsch recorreu, inicialmente, à teoria econômica, mas, em seguida, voltou-se para as teorias sociais em competição para fazer justiça às exigências políticas, científicas e artísticas.

17. Cf. Grundmann (2011, pp. 111-162); de uma perspectiva do direito comparativo, ver introdução em Cafaggi (2011, pp. 1-11). 
18. Sobre dupla atribuição em redes tanto da perspectiva das ciências sociais como do direito, ver Teubner (2011, p. 154 - inclui também referências detalhadas; 2013, pp. 124 e ss.).

19. Sobre conflitos de racionalidades em redes intersistêmicas, ver Amstutz (2013, pp. 319 e ss., 350 e ss.; 2009 , pp. 335 e ss.) e Teubner (2009, pp. 28 e ss.).

20. Para a discussão europeia sobre "interesse do grupo corporativo", ver Drygala (2013, p. 198 e ss.). maior do que qualquer mera minimização dos custos de transação. Ele deve ser compreendido como uma orientação múltipla, que incorpora, por um lado, um compromisso com os vários projetos individuais dos participantes da rede e, por outro, com o projeto global da rede como um todo ${ }^{18}$. Com uma abordagem transversal, o direito reage sucessivamente aos impulsos provenientes de teorias parciais econômicas, políticas, sociológicas, éticas e outras. No final, ele entende redes intersistêmicas como arranjos organizacionais nos quais o conflito entre diferentes racionalidades sociais é, na verdade, institucionalizado. Um conceito jurídico de finalidade da rede que é definido dessa forma obriga os atores a ajustarem seu comportamento a lógicas de ação diferentes e contraditórias. No caso da rede de pesquisa público-privada, os participantes são obrigados, simultaneamente, embora com prioridades diferentes, a levar em consideração quatro imperativos categóricos mutuamente exclusivos, quais sejam: as exigências contraditórias de capacidade econômica de lucro, o conhecimento científico, as normas médicas e o foco político sobre o bem comum. De fato, como várias teorias sociais têm afirmado, como resultado de sua natureza híbrida, as redes parecem ser quase feitas sob medida para absorver várias racionalidades contraditórias entre si, permitindo a interferência mútua sem qualquer classificação hierárquica ${ }^{19}$.

Um direito de redes pode responder a tais desafios? Em vez de simplesmente promover a minimização dos custos de transação, uma constituição legal de redes terá que desenvolver princípios de autonomia institucional, direitos fundamentais, imparcialidade processual e regras de direito e de responsabilidade política para esse misto de configurações público-privadas (Teubner, 2009). A forma jurídica da rede não deve reconhecer qualquer teoria social como detentora de um monopólio - não deve haver exclusividade para a redução dos custos de transação, para a orientação política, para a aquisição de conhecimento científico ou para padrões éticos de comportamento. Em vez disso, essa forma legal deve procurar cobrir a multidimensionalidade das redes, explorando diferentes teorias sociais. É vedado ao direito aceitar o domínio de qualquer racionalidade social parcial.

Uma orientação múltipla similar já foi desenvolvida no conceito legal de "interesse do grupo corporativo" (Emmerich e Habersack, 2013, $₫ 18$, n. 7; $₫$ 311 , n. 47-50; \$311, n. 77-81; Hoffmann-Becking, 2012, p. 441 e ss. ${ }^{20}$. Não é novidade que grupos corporativos sejam redes exatamente da mesma maneira como as redes contratuais que estamos abordando aqui. Mas em contraste com o direito dos grupos empresariais, que, além das garantias legais de autonomia das subsidiárias, também protegem os interesses puramente econômicos das 
subsidiárias contra a matriz e vice-versa ${ }^{21}$, há muito mais em jogo no caso das redes intersistêmicas. No nosso exemplo, não é apenas a aquisição de lucro que pode ser considerada a finalidade legal da rede, mas também a integridade institucional das instituições de pesquisa, das instalações médicas, dos investidores privados e da administração pública deve ser respeitada na estrutura descentralizada de uma rede. Enquanto nos grupos empresariais ainda faz sentido formular um interesse corporativo econômico comum, que seja compartilhado por todas as empresas participantes sob a forma de normas jurídicas processuais e materiais, uma finalidade da rede em cooperações de PPP pode consistir apenas no processo de busca por um espaço de compatibilidade de diferentes racionalidades.

A finalidade associativa de redes intersistêmicas encontra sua expressão jurídica - em paralelo com a finalidade do contrato e a finalidade social -, entre outros exemplos, na sanção de deveres de lealdade diante dos participantes da rede $^{22}$. Esses deveres aplicam-se tanto em relação aos outros participantes (e requerem, portanto, que os interesses deles sejam considerados em separado), como em relação à rede como um todo (eles são, portanto, direcionados ao sucesso do projeto como um todo ${ }^{23}$. As manipulações dos resultados de pesquisa, que, nas circunstâncias do caso que descrevemos, foram conduzidas com base em seus respectivos interesses distintos pela agência de comunicação em cooperação com a empresa farmacêutica e a fundação científica responsável pela realização dos estudos clínicos, foram uma violação flagrante das duas formas de dever de lealdade, e pedem sanções legais drásticas. Ao contrário da finalidade do contrato ou da finalidade social, a finalidade da rede impóe a obrigação de promover as diferentes racionalidades envolvidas e, ao mesmo tempo, equilibrar umas às outras. Em contraste com o equilíbrio tradicional de interesses no caso individual, o resultado da abordagem da transversalidade seria o de que diferentes racionalidades sociais seriam examinadas em um processo de equilíbrio legal.

\section{Tese 2: responsividade}

A abordagem distanciada é recomendada também sob outro aspecto. Se o direito, no processo transverso, al cançou uma decisão por meio de seus contatos com as teorias sociais, então estas requerem que seus conhecimentos possam ser transpostos para o direito sem que sejam de forma alguma modificados. A doutrina jurídica em particular (seu caráter científico é, em qualquer caso, duvidoso) parece ser aqui a culpada pela ofuscação ${ }^{24}$. Assim, inspirado pela
21. Apenas as abordagens de direito corporativo informadas sociologicamente vão além desta orientação de única tessitura (Amstutz, 1993).

22. A responsabilidade das redes externas é a outra área do direito para a qual as normas adequadas à rede devem ser desenvolvidas; ver Teubner (2011, pp. 235 e ss. - inclui referências detalhadas).

23. Para uma análise da perspectiva do direito comparativo, ver Weitzenboeck (2012, pp. 186 e ss.).

24. Sobre a questão problemática da natureza científica da jurisprudência, há um resumo da discussão em F. Röhl e C. Röhl (2008, pp. 79 e ss.). 
25. Loci classici: Cohen (1935, pp 809 e ss.); Kennedy (1975, pp. 1685 e ss.); Posner (1987, pp. 761 e ss.) e Albert (1993).
26. A distinção é importante. Autonomia relativa significa que dependência $e$ independência são baseadas no mesmo mecanismo; uma relação de reforço mútuo é possível se dependência e independência são atribuíveis a diferentes mecanismos. A independência do direito é baseada na interligação dos atos jurídicos, enquanto a dependência é baseada nos desafios apresentados aos programas legais. polêmica de Jhering contra a jurisprudência conceitual, o realismo jurídico norte-americano ridicularizou a doutrina tradicional como "transcendência sem sentido" e substituiu-a por uma concepção de direito (baseada na teoria política) como uma política social orientada para as consequências. Estudos jurídicos criticos têm intensificado o "sucateamento" da doutrina com base na teoria social crítica e exigido a aberta politização de conflitos legais. O principal representante da teoria do direito econômico, Richard Posner, nega qualquer contribuição autônoma da doutrina jurídica para o estabelecimento racional de normas e pede para que a orientação moral-política obsoleta seja substituída por critérios de eficiência econômica. Outros autores, por sua vez, requerem a unidade das ciências sociais, entre as quais a jurisprudência como uma "ciência real" é apenas uma de suas subseções e não tem estatuto independente ${ }^{25}$.

Isso deve ser vigorosamente contestado: qualquer transferência autêntica de conhecimento a partir da teoria social para o direito esbarra em uma impossibilidade. Ela fracassa por causa da autonomia inflexível do sistema legal. Esta é a lição não apenas da doutrina jurídica tradicional, mas também da teoria avançada dos sistemas (Luhmann, 2004, pp. 455 e ss.; Vesting, 2007, pp. 141 e ss.). A diferenciação funcional da sociedade, tratada anteriormente, engloba o próprio direito, bem como os outros sistemas sociais. Apoiado pela validade exclusiva do "código binário" lícito/ilícito, o direito desenvolve uma estrutura complexa de conceitos que chamamos de "doutrina”, que é, de fato, incomensurável com teorias científicas. $\mathrm{O}$ código jurídico, que é diferente de outros “códigos binários" da sociedade, constitui a base da autonomia inevitável da doutrina jurídica, a qual exclui categoricamente qualquer tomada de poder unilateral por parte das teorias sociais.

No entanto, tendo em vista a interdependência das racionalidades sociais, é necessária uma interligação entre teoria social e doutrina. Mas esta interligação só pode surgir com base na autonomia de ambos os lados. É, portanto, um equívoco falar de autonomia relativa do direito; pelo contrário, existe uma relação de intensificação mútua entre a autonomia do direito e sua interdependência com outros sistemas sociais ${ }^{26}$. Em primeiro lugar, isso significa uma estrita divisão de tarefas entre dois processos de busca independentes: as teorias sociais fornecem análises estruturais de fenômenos sociais, identificam problemas sociais que são gerados por esses fenômenos em seu ambiente e são capazes de fornecer informações diretivas com vistas a encontrar possíveis soluções para os problemas que submetem a uma comparação funcional. Isso é algo com o que a doutrina jurídica pode se conectar caso (diacronicamente, na dependência da trajetória dos conceitos jurídicos historicamente desen- 
volvidos, e, sincronicamente, no contexto do código legal e dos programas jurídicos existentes) ela desenvolva normas independentes.

A interconexão entre o direito e as ciências sociais vai além da mera demarcação de fronteiras territoriais no momento em que a doutrina legal começa a examinar cuidadosamente diferentes instituições jurídicas para determinar se, em termos de sua lógica normativa interna - de sua "base interna", como os juristas formulariam -, elas são capazes de responder com sensibilidade às estruturas e aos problemas dos fenômenos sociais tais como percebidos pelo direito. Essas operações de busca sutis, que são realizadas com o auxílio dos conceitos sensitivos da doutrina, devem ser referidas aqui pelo emprego do termo "responsividade" (Nonet e Selznick, 1978). A responsividade do direito não deve ser julgada perante um fórum das ciências sociais que pudesse garantir o uso autêntico do termo, ou perante um fórum de uma terceira instância superordenadora que agiria como intermediária entre o direito e a teoria social, mas apenas perante o forum internum do próprio direito. Em um exame complexo, o direito deixa-se desafiar pelas análises externas de problemas das teorias sociais, mas isso apenas se elas são passíveis de utilização conforme os próprios critérios de seleção do direito; então, ele as reconstrói internamente em sua própria língua, na qual ele pode, assim, conciliar problemas e soluções entre si. Somente quando esse processo de reconstrução coloca a argumentação jurídica em uma posição na qual ela possa distinguir dentro do direito entre normas e fatos, entre conceitos jurídicos e interesses sociais, é que se alcança um ponto no qual o direito é capaz de levantar a questão da adequação social, em outras palavras, a questão de saber se as decisões judiciais fazem justiça a esses aspectos do mundo exterior, tal como estes foram reconstruídos internamente ${ }^{27}$.

Este processo requer mais um estágio, ou seja, uma estimativa previsível de como a mudança da norma jurídica será aceita no mundo social (Amstutz, 2013, pp. 324 e ss.). Por meio do monitoramento subsequente dos "efeitos do direito no mundo social", essas estimativas serão corrigidas quando conflitos sociais semelhantes forem novamente trazidos perante o direito e as modificações forem procuradas no curso de longas cadeias de jurisprudência. O direito pretende, assim, compensar o efeito de alienação resultante do fato de ele reconstruir conflitos sociais em sua linguagem autônoma e produzir soluções que são apenas internas a ele. Deve-se enfatizar mais uma vez que esse monitoramento envolve operações de observação do ambiente que são internas ao direito. Aqui, análises feitas pela ciência social do efeito exercido pelo direito podem novamente impor desafios a ele e modificar a simples operação de monitoramento via cadeias de jurisprudência. A responsividade do direito
27. Sobre a "promulgação" do meio ambiente como uma alternativa para a sua "representação", ver Varela (1992, pp. 235 e ss.). 
28. Sobre a conexão entre "re-entry" e "espaço imaginário", ver Brown (1972); em relação à aplicação do direito e seus ambientes, ver Luhmann (2004, pp. 105 e ss.).

29. Os conflitos precisam ser alimentados, não eliminados; ver Hensel (2009, pp. 521 e ss.).

30. Sobre a ligação entre desafio, reconstrução e valor agregado simbólico em geral, ver Mölders (2012, pp. 18 e ss.); e especificamente nas relações entre teoria social e direito, ver Teubner (2000, pp. 407 e ss.). em relação às ciências sociais, portanto, não se limita à reconstrução de conflitos antes da decisão judicial, mas estende-se à observação das consequências dessas decisões conforme elas surgem no seio da sociedade.

Por isso, a recepção legal de teorias sociais nunca é uma tomada de poder autêntica, mas sempre uma re-entry (reentrada) da diferença sistema/ambiente, por meio da qual um espaço imaginário surge no direito, ou seja, é sempre uma reconstrução jurídica interna de demandas externas feitas pela sociedade, pelas pessoas e pela natureza ${ }^{28}$. Responsividade, como uma capacidade do direito de ser desafiado por teorias sociais, não é de modo algum uma "comporta" através da qual - conforme coloca Niklas Luhmann - "o conhecimento social poderia cada vez mais e, por assim dizer, sem constrangimentos, fluir para o direito. Pelo contrário, a tensão está na subjetividade do sistema, caso se possa formular assim, e, por conseguinte, na relatividade inevitável de todas as perspectivas do sistema" (Luhmann, 1992a, p. 397). O conflito entre direito autônomo e teoria social autônoma não é, em princípio, insuperável; ele é, na verdade, desejável ${ }^{29}$. Para usar uma formulação exagerada, ele apenas pode ser superado por meio de um mal-entendido produtivo dentro do direito. $\mathrm{O}$ mal-entendido é inevitável e torna-se produtivo quando a doutrina jurídica trata as teorias sociais como "desafios" externos, mas, em vez de descartá-las em isolamento esplêndido, as reconstrói dentro de si, formando seus próprios conceitos, e responde a elas com a formação autônoma de normas.

Se a "tradução" da teoria social na doutrina jurídica é realizada dessa forma, então ela tem o potencial de gerar valor agregado em termos de doutrina jurí$\operatorname{dica}^{30}$. O processo não ocorre como mera transferência de significado idêntico para outra linguagem, mas de tal forma que a própria terminologia do direito se permite ser desafiada, de acordo com as condições de sua lógica de desenvolvimento interior, por construções da teoria social e, em consequência, ser inspirada a criar novas formações estruturadas de modo bastante diferente. É apenas a sequência (executada dentro do direito) de desafio/reconstrução/ mudança da norma/observação do efeito que gera o valor doutrinal agregado que não pode ser alcançado nem na autoimunização da doutrina jurídica, nem na transferência direta de construções teóricas sociais para o direito.

Onde estaria o valor doutrinal agregado no âmbito da rede de PPP no que diz respeito às questões legais que levantamos no início deste artigo? "Rede" não é um conceito jurídico. Não há nenhuma maneira de que o princípio da eficiência, com base no qual os economistas analisam as redes como híbridos entre mercado e hierarquia, seja capaz de servir como um princípio jurídico orientador, muito menos como uma norma legal diretamente aplicável. Nem 
o pode o "enraizamento social" das transações econômicas, que os sociólogos enfatizam como o traço característico do enredamento ${ }^{31}$. Em vez disso, é necessária uma estrita divisão de tarefas. As teorias sociológicas e econômicas identificam a lógica idiossincrática de ação das redes, revelam oportunidades e os riscos da sua dinâmica e abrem alternativas de soluções estruturais que vão além do mercado e da hierarquia. $\mathrm{O}$ direito contratual se permite, assim, ser desafiado, reconstrói problemas de rede na linguagem da doutrina jurídica, e, com base em suas próprias tradições, desenvolve normas e princípios para as redes que podem servir como soluções jurídicas adequadas para os novos problemas de coordenação e de responsabilidade.

$\mathrm{O}$ verdadeiro desafio para o direito responsivo é descobrir qual entre as várias instituições do direito privado historicamente desenvolvidas é a mais provável detentora do potencial normativo para a elaboração de normas adequadas à rede. Qual instituição jurídica é capaz de alcançar, para além dos acordos bilaterais, um compromisso legal que abranja todas as partes da configuração conjunta? Os candidatos potenciais são: sociedade (empresarial) simples [BGB-Gesellschaft], rede contratual, base do negócio (jurídico) [Geschäftsgrundlage], contrato de proteção de terceiros, contrato de efeito vinculante. As regras do direito societário não são adequadas para as redes, uma vez que incluem a orientação exclusiva para a finalidade social (da empresa), e teriam de classificar como ilegal a orientação simultânea aos interesses individuais, que é uma característica das redes. A construção de uma rede contratual celebrada entre todos os participantes deixa de apreciar a realidade jurídica das redes, uma vez que tem de inventar uma multiplicidade de ficções legais no que diz respeito à representação e à autorização de todas as partes por todas as partes ${ }^{32}$. As regras de base do negócio (jurídico) [Geschäftsgrundlage] têm de ser excluídas, pois o contrato somente é direcionado para a execução e não pode gerar quaisquer deveres legais positivos (sugestão de Grundmann, 2008, pp. 227 e ss.). Um contrato com efeito protetor em favor de terceiros gera, de fato, efeitos obrigatórios em relação a terceiros, mas não é adequado para as relações multilaterais e não tem a orientação para o desempenho contratual que é necessária em uma rede (sugestão de Lange, 1998, pp. 195 e ss.). A doutrina dos contratos de efeito vinculante, desenvolvida para acordos de compra financiados, mostra-se a mais adequada para as redes, uma vez que ilustra precisamente a tensão entre os contratos individuais independentes e sua interligação recíproca; ela formula a orientação dupla típica da rede para os nós da rede e para a rede como um todo - e estabelece três condições precisas para contratos conectados: 1) referências mútuas (implícitas) entre
31. Sobre "rede" em um contexto econômico, ver Williamson (1991, pp. 180 e ss.) e, em um contexto sociológico, ver Powell (1990, pp. 295-336).

32. Sobre a construção de um contrato de rede global, ver Rohe (1998). 
33. Sobre este ponto, novamente sugiro Amstutz (2013, pp. 330 e ss.). $\mathrm{O}$ autor identifica autocorreções sutis nos estágios iniciais de uma cadeia de jurisprudência da suprema corte alemã para redes contratuais.

34. Um exemplo notável encontra-se em Habermas (1963, especialmente pp. 231 e ss.).

35. Ver Luhmann (1990, pp. 627 e ss.). O sistema da ciência também desenvolve orientações normativas, mas apenas para a sua própria prática.

36. Para mais sobre esse ponto, ver Teubner (2014). os contratos bilaterais; 2) finalidade contratual comum; 3) cooperação de fato (Teubner, 2011, pp. 158 e ss.). Rede versus vínculo contratual - a diferença entre a teoria social e a classificação jurídica tem o potencial para a geração do valor doutrinal agregado que estamos procurando. A questão de saber se o vínculo contratual representa a solução jurídica adequada para os conflitos que surgem nas redes acabará por ser decidida pela forma como o direito observa os efeitos de suas decisões no mundo social ${ }^{33}$.

\section{Tese 3: autonormatividade}

Por fim, nosso caso de "viés de publicação" levanta um problema mais difícil: o direito pode obter critérios normativos das teorias sociais - no nosso caso, para efeitos de direitos fundamentais em redes públicas de economia mista? Defensores atuais da unidade entre teoria e prática veem isso como a sua mais nobre tarefa, ou seja, revelar, em uma análise da sociedade como um todo, potenciais normativos para o desenvolvimento social que forneçam informações diretrizes para a política e para o direito ${ }^{34}$. E requerem das teorias dos sistemas normativamente frias, acima de tudo, a realização de uma "guinada normativa", caso queiram emitir postulados relevantes para o direito (Francot-Timmermans e Christodoulidis, 2011, pp. 187 e ss.).

No entanto, aqui também - pela terceira vez - somos forçados, pela diferenciação funcional da sociedade, a fazer uma correção. Essa diferenciação destrói irreversivelmente a velha unidade europeia de teoria e prática, restringindo a ciência a uma codificação verdadeiro/falso exclusiva, que não permite que as teorias sociais possam (em vez de meras declarações cognitivas) também fazer postulações normativas no código da política, da moralidade ou do direito. Por princípio, as ciências sociais não podem abastecer outros contextos de ação com critérios normativos ${ }^{35}$. Recomendações normativas são sempre questões transcientíficas (Weinberg, 1972, pp. 209 e ss.).

De uma forma particularmente dolorosa, essa autorrestrição também afeta a filosofia, da qual o direito (a despeito dos grandes esforços de Rawls e Habermas) não pode esperar qualquer importação de normatividade. A filosofia não pode escapar do "trilema" de Münchhausen da fundação de normas - regressão infinita, interrupção, circularidade. Em última análise, todas as tentativas de fundação normativa deparam-se com paradoxos. No entanto, a "desparadoxização" não pode ser efetuada pela filosofia com um disfarce normativo, mas apenas por práticas sociais na comunicação e por indivíduos em sua introspecção ${ }^{36}$. A consequência deste fracasso da teoria é a autonor- 
matividade. Ela vem à tona em dois processos completamente diferentes: a autonormatividade jurídica forma-se nos procedimentos internos ao direito e a autonormatividade das práticas sociais (para a qual o direito pode recorrer) forma-se nos procedimentos externos ao direito.

O próprio direito é uma das práticas sociais que geram sua autonormatividade sem depender de sua base científica ou filosófica. Esta conclusão nos é imposta pela (para citar alguns autores importantes) norma fundamental de Hans Kelsen, pela visão interna de Herbert Hart e pelo código binário do direito de Niklas Luhmann (Kelsen, 1990; Hart, 1981, pp. 55 e ss.; Luhmann, 2004, pp. 165 e ss.). As funções jurídicas de autonormatividade funcionam como autorreprodução de normas com base no direito vigente e como produção de normas de desvio de acordo com as condições em que o direito opera. E é apenas no âmbito desta autonormatividade jurídica que a teoria social pode se tornar normativamente relevante (embora apenas no contexto de desafio e reconstrução, conforme descrito anteriormente).

No entanto, essa autorreprodução do sistema legal gera apenas um tipo de autonormatividade, ou seja, aquela que é interna ao direito. Externamente a ele, a autonormatividade de outras práticas sociais complementa a produção interna de normas, na medida em que o direito recorre a elas. Os sistemas sociais geram não só a sua racionalidade própria - racionalidade no sentido de Max Weber -, mas também a sua autonormatividade. Isso foi demonstrado mais claramente por Lon Fuller, que descreve a moralidade das associações como um fenômeno emergente da comunicação social. No entanto, de Wittgenstein a Lyotard, essa percepção tornou-se conhecimento comum na filosofia linguística. A normatividade de um grande número de jogos de linguagem é baseada em suas "formas de vida" [Lebensform] e não é acessível a qualquer justificação última. De uma forma muito semelhante, o institucionalismo identifica práticas sociais como geradoras de conjuntos de norma, sob a orientação de uma idée directrice (Fuller, 1983; Lyotard, 1987; Hauriou, [1933]1986, pp. 89-128).

Neste ponto, torna-se claro que o motivo condutor para um encontro interdisciplinar entre o direito e as teorias sociais não é, com segurança, primeiramente um contato com a academia, mas o contato com a sociedade. Para além da sua autonormatividade, o direito procura orientação normativa em diferentes ambientes e em suas normas locais e, além disso, pede ajuda às teorias sociais. No entanto, após uma inspeção mais exata, verifica-se que grande parte do que leva o nome de teoria social não é uma teoria científica em sentido estrito, mas uma prática de reflexão sobre diferentes mundos sociais ou, talvez mais precisamente, uma “dogmática de reflexão”, similar 
37. Isso é particularmente notável no caso das normas institucionalizadas das profissões. A esse respeito e com os resultados de pesquisa empírica, ver Herberg (2011, pp. 107-129).

38. Ladeur, em particular, sublinha repetidas vezes quão fortemente o direito depende de uma “epistemologia social", ou seja, do conhecimento das práticas sociais (Ladeur, 2006). Além dele, ver Augsberg (2014, cap. 6). Sobre a influência "subcutânea" do decoro da arte na jurisprudência para questōes dos direitos da personalidade, ver Steinhauer (2009, pp. 174 e ss.). à teologia e à dogmática jurídica, o que gera orientações normativas nas práticas sociais.

A normatividade jurídica sempre se desenvolve em contato com essa dogmática de reflexão de outros setores da sociedade. Por isso, é importante evitar o mal-entendido cientificista, que é promovido pelas declaraçóes programáticas da jurisprudência sociológica, pela teoria política jurídica ou pela economia jurídica, que se consideram como ciências sociais. A despeito do quão importante as ciências sociais são para a responsividade do direito (como foi demonstrado anteriormente), o foco está aqui em outro lugar: em orientações normativas que, por princípio, não podem ser fornecidas pelas ciências sociais "imparciais", mas apenas pela "dogmática" normativamente preenchida das práticas sociais. Assim como a dogmática jurídica ou a teologia (a mãe de todas as dogmáticas) não são ciências, mas autorreflexões das práticas sociais do direito ou da religião que foram sistematizadas como sistemas dogmáticos, também as grandes áreas da economia empresarial, ciência econômica e ciência política não são partes das ciências sociais que devem observar o código binário verdadeiro/falso, mas dogmáticas de reflexão de "mundos de sentido" sociais, que aparecem sob a forma de teorias sociais científicas, ou seja, como dogma relativo à maneira correta de agir no mundo dos negócios, na indústria ou na política, compartilhando e informando as respectivas orientações normativas básicas de suas práticas. Em todo caso, uma diferenciação interna clara deve ser feita entre as disciplinas acadêmicas (assim como, na jurisprudência, é feita uma distinção entre a teoria jurídica, como uma reflexão interna sobre a prática, e a sociologia jurídica, como uma observação científica externa do direito) em discursos que, como dogmáticas de reflexão, devem ser alocados às respectivas práticas sociais e em discursos que, como teoria social em sentido estrito, devem ser alocados ao sistema da ciência.

$\mathrm{O}$ direito procura contato com a autonormatividade das práticas sociais, que são refinadas em dogmáticas de reflexão da prática econômica e social ${ }^{37}$. Em comparação com o mal-entendido cientificista anteriormente referido, o ganho é duplo. A orientação para dogmáticas sociais de reflexão oferece uma riqueza de perspectivas normativas, desde idées directrices abstratas de instituições sociais até expectativas sociais concretas, reivindicações, justificação de direitos básicos e esperanças individuais das pessoas envolvidas, passando por percepçóes dos sistemas sociais obtidas coletivamente de acordo com sua capacidade de desempenho e por definições de sua função social global ${ }^{38}$. Isso nunca poderia ser gerado pelas teorias sociais "livres de pressupostos" e "livres de preconceitos", mas também não poderia jamais ser concebido pela 
doutrina jurídica em seus próprios termos. Ao mesmo tempo, no entanto, há mais uma vez possibilidades de distanciamento para o direito, se ele faz valer suas próprias orientações "parcialmente universais" por meio de controles jurídicos. O navio que navega sob a bandeira da abordagem científica como jurisprudência sociológica, economia jurídica, política jurídica e ética jurídica deveria, na realidade, abaixar as bandeiras para fazer justiça ao conflito entre diferentes dogmáticas de reflexão.

Para retornar mais uma vez ao tema da filosofia moral: é possível, então, introduzir Rawls ou Habermas para a justificação das normas jurídicas? Depende. Não, na medida em que eles pretendem produzir uma teoria social em sentido estrito, uma vez que (ao contrário dos seus próprios entendimentos) não podem instituir quaisquer normas no código de verdade da ciência. Sim, na medida em que ambos os filósofos podem ser entendidos como participantes na prática moral ou na prática política e ajudam a configurar dogmáticas de reflexão delas. Mesmo como tais, eles ainda não são, de maneira direta, juridicamente relevantes, mas devem primeiro passar pelo filtro jurídico da teoria do direito, da doutrina legal e da prática de tomada de decisão judicial.

Voltemos uma última vez para o problema do viés de publicação. O que a interação entre a autonormatividade do direito e a autonormatividade das instituições sociais significa para a eficácia horizontal dos direitos fundamentais em redes privadas? A resposta, em suma, é: as normas devem ser estabelecidas para a proteção institucional de expertises, por um lado, e para a integridade do sistema de saúde contra as tendências expansionistas da racionalidade econômica, por outro.

O efeito horizontal dos direitos fundamentais não pode ser estabelecido com base em teorias sociais, mas é inicialmente um produto de operações que ocorrem dentro do direito. $\mathrm{O}$ princípio da igualdade, como princípio fundamental da autonormatividade do direito, requer que a proteção dos direitos fundamentais seja garantida não só em relação às instâncias governamentais, mas também em relação às redes privadas, caso esses direitos sejam, similarmente, postos em risco em situações que envolvam o poder privado ${ }^{39}$. As manipulações que desencadeiam o viés de publicação - a proibição de publicação e a falsificação dos resultados da investigação - violam o direito fundamental da liberdade acadêmica e o direito fundamental à saúde. No entanto, como é demonstrado pelos protestos veementes daqueles que defendem a santidade do direito privado contra qualquer tipo de eficácia horizontal de direitos fundamentais, é problemático pensar se uma proteção efetiva de tais direitos pode ser alcançada através do equilíbrio entre os direitos individuais,
39. De acordo com a doutrina predominante, os direitos fundamentais propagam-se (indiretamente) nas relaçôes de direito privado caso surja uma situação estrutural de perigo devido ao poder social, por exemplo, nas estruturas de monopólio, nas relaçōes de arrendamento mercantil e nas relaçốes de trabalho. Sobre este tema, ver, em detalhes, Maunz e Dürig (2013, art. 1, §3, leis 59-65). 
40. Na discussão sobre a eficácia horizontal de direitos fundamentais [Drittwirkung], os direitos fundamentais individuais são geralmente equilibrados uns contra os outros; a dimensão institucional de direitos fundamentais é aqui raramente usada. Ver Hensel (2009, pp. 517 e ss.).

41. Vesting (2007, pp. 95 e ss.) fala em "convenções sociais e conhecimento implícito".
42. Os Estados Unidos aparecem como modelo com o "FDA [Food and Drug Administration] Amendments Act,, 2007", Lei Pública n. 110-85, § 801 (disponível em www.gpo.gov/fdsys/ pkg/PLAW-110publ85/pdf/ PLAW-110publ85.pdf).

43. Exemplos iniciais são fornecidos pelo registro do governo dos Estados Unidos (ClinicalTrials. gov) e pelo Deutsche Register Klinischer Studien [Registro alemão de estudos clínicos] da Universitätsklinikum Freiburg (www.germanctr.de).

44. De Angelis, Drazen, Frizelle et al. (2004, pp. 1250 e ss.). Há também algumas publicações na internet que veiculam principalmente estudos negativos, por exemplo, o Journal of Negative Results in Biomedicine (www.jnrbm.com). conforme previsto pela doutrina predominante - Zöllner (1993, pp. 1 e ss.) é particularmente crítico. Uma maneira de sair desse dilema é deslocar a proteção dos direitos fundamentais contra o poder privado do nível individual para o nível institucional. O efeito horizontal dos direitos fundamentais (no nosso caso, o direito à liberdade acadêmica e o direito à saúde) é, então, garantido não por direitos individuais com base nos quais ações jurídicas podem ser movidas, mas pela organização e processo que preservam seu aspecto institucional ${ }^{40}$.

A questão acerca de qual organização e quais processos podem ser usados para proteger as instituições da ciência e do sistema de saúde já não é, portanto, passível de resposta dentro do direito. O conteúdo normativo de tais garantias institucionais só pode ser obtido a partir de fora do direito, a partir da autonormatividade da prática social. Ciência e sistema da saúde, em seus códigos e programas separados, dão origem a orientações normativas que não são as mesmas que as opiniões convencionais de indivíduos, mas têm um caráter institucional ${ }^{41}$. Uma normatividade institucional desse tipo está embutida em estruturas historicamente desenvolvidas, reativadas na dogmática de reflexão da ciência e do sistema da saúde e reformadas nas decisões e nos debates "políticos" antes de serem absorvidas pelo direito.

Para as manipulações do viés de publicação, os discursos reflexivos da ciência e do sistema da saúde elaboraram, de fato, uma alternativa institucional para a proteção individual: registro de testes como eficácia horizontal de direitos fundamentais nos casos do direito de liberdade acadêmica e do direito à saúde através da organização e do processo ${ }^{42}$. Registros públicos de estudos e resultados estão sendo criados. Eles recobrem todos os aspectos dos experimentos desde o seu início para facilitar a transparência e o controle ${ }^{43}$. Ao mesmo tempo, revistas especializadas estão tornando o registro de todos os estudos realizados um pré-requisito para a publicação ${ }^{44}$. Estudos clínicos em relação aos produtos que são destinados à distribuição no mercado devem, antes, ser inscritos no registro de testes clínicos com todos os resultados.

\section{Conclusão}

Tentamos mostrar aqui, de uma maneira geral e empregando o exemplo do efeito horizontal dos direitos fundamentais nas redes semiprivadas, que, no ponto em que a teoria social encontra o direito, pode ser gerado um valor agregado em termos de doutrina jurídica, caso a relação precária entre autonomia e a interdependência nas três diferentes dimensões seja respeitada. 
1. A transversalidade tira conclusões a partir da autonomia das diferentes e incomensuráveis teorias sociais e de sua interconexão mútua. $\mathrm{O}$ direito nega qualquer pretensão de monopólio e seleciona os pontos de contato em uma exploração transversal.

2. A responsividade insiste na autonomia da doutrina jurídica em relação às teorias sociais e justifica sua interligação com elas na medida em que o direito se abre aos desafios que tais teorias colocam, deixa-se inspirar por elas para a inovação normativa e observa seus efeitos sobre o mundo social.

3. Autonormatividade: o direito não alcança a orientação normativa a partir da teoria social, mas unicamente de processos internos a ele e, ao mesmo tempo, a partir da autonormatividade desenvolvida pelas dogmáticas de reflexão de outros sistemas sociais.

Especificamente no caso do viés de publicação, nas circunstâncias do nosso caso, diferentes construções doutrinárias - uma "finalidade da rede", que é diferente da finalidade do contrato e da finalidade social (da empresa); a vinculação contratual como um conceito jurídico para as redes; uma garantia institucional do efeito horizontal dos direitos fundamentais por organização e processo sob a forma de registro dos experimentos - podem ser consideradas a evolução jurídica socialmente adequada que surge na abordagem distanciada de teorias da rede adotadas pelo direito.

\section{Referências Bibliográficas}

Albert, Hans. (1993), Rechtswissenschaft als Realwissenschaft: das Recht als soziale Tatsache und die Aufgabe der Jurisprudenz. Baden-Baden, Nomos.

Amstutz, Marc. (2009), "The constitution of contractual networks". In: Amstutz, Marc \& Teubner, Gunther (orgs.). Contractual networks: legal issues of multilateral cooperation. Oxford, Hart, pp. 309-346.

. (2013), "The nemesis of European private law: contractual nexus as a legislative conundrum”. In: Grundmann, Stefan; CAfaGgi, Fabrizio \& VetTori, Giuseppe (orgs.). The organizational contract: from exchange to long-term network cooperation in European contract law. Londres, Ashgate, pp. 319-356.

Amstutz, Marc (1993). Konzernorganisationsrecht: Ordnungsfunktion, Normstruktur, Rechtssystematik. Bern, Stämpfli.

Applegate, William; Furberg, Curt; Grimm, Richard \& Byington, Robert. (1996),

"The Multicenter Isradipine Diuretic Atherosclerosis Study (MIDAS)". Journal of the American Medical Association, 277: 297-298. 
Augsberg, Ino. (2014), Informationsverwaltungsrecht: zur kognitiven Dimension der rechtlichen Steuerung von Verwaltungsentscheidungen. Tübingen, Mohr Siebeck.

Brodocz, André \& SCHAAL, Gary. (2009), Politische Theorien der Gegenwart. Stuttgart, Opladen.

Brown, George Spencer. (1972), Laws of form. Nova York, Crown.

Butler, Brian E. (2011), "Law and economics, internet encyclopedia of philosophy". Disponível em www.iep.utm.edu/law-econ.

CASTElls, Manuel (2000). The rise of the network society. Oxford, Wiley.

CAfaggi, Fabrizio. (2011), "Introduction”. In:___ (org.). Contractual networks, inter-firm cooperation and economic growth. Cheltenham, Edward Elgar.

Cohen, Felix S. (1935), "Transcendental nonsense and the functional approach". Columbia Law Review, 35: 809-849.

Dahrendorf, Ralf. (1958), Homo sociologicus: Ein Versuch zur Geschichte, Bedeutung und Kritik der sozialen Rolle. Stuttgart, Opladen.

De Angelis, C.; Drazen, J. M.; Frizelle, F. A. et al. (2004), "Clinical trial registration: a statement from the International Committee of Medical Journal Editors". The New England Journal of Medicine, 351: 1250-1251.

Drygala, Tim. (2013), "Europäisches Konzernrecht: Gruppeninteresse und Related Party Transactions". Die Aktiengesellschaft, 16: 198-210.

EIdenmüller, Horst. (1995), Effizienz als Rechtsprinzip. Tübingen, Mohr Siebeck.

EMmerich, Volker \& Habersack, Mathias. (2013), Aktien-und GmbH-Konzernrecht-Kommentar. Munique, C. H. Beck.

EYDING, Dirk et al. (2010), "Reboxetine for acute treatment of major depression: systematic review and meta-analysis of published and unpublished placebo and selective serotonin reuptake inhibitor controlled trials". BMJ, 341: c4737.

Francot-Timmermans, Lyana \& Christodoulidis, Emilios A. (2011), "The normative turn in Teubner's systems theory of law". Rechtsflosofie \& Rechtstheorie, 40: 187-190.

Fuller, Lon. (1983), Principles of social order: selected essays of Lon L. Fuller. Durham, Hart.

Gómez, Fernando. (2011), "Cooperation, long-term relationships and open-endedness in contractual networks”. In: CAFAG GI, Fabrizio (org.). Contractual Networks, Inter-Firm Cooperation and Economic Growth. Cheltenham, Edward Elgar.

Gordley, James. (2008), “The State's private law and legal academia”. In: JANSEN, Nils \& Michaels, Ralf(orgs.). Beyond the State: rethinking private law. Tübingen, Mohr Siebeck, pp. 219-232.

Grundmann, Stefan. (2008), "Vertragsnetz und Wegfall der Geschäftsgrundlage”. In: Aderhold, Lutz; Grunewald, Barbara; Klingberg, Dietgard \& Paefgen, Walter G. (orgs.). Festschrift für Harm Peter Westermann zum 70. Geburtstag. Colônia, Dr. Otto Schmidt, pp. 227-244. 
. (2011), "Contractual networks in German private law”. In: CAFAG GI, Fabrizio (org.). Contractual networks, inter-firm cooperation and economic growth. Cheltenham, Edward Elgar, pp. 111-162.

GüNTHER, Gotthard. (1976), "Life as poly-contexturality”. In: Beiträge zur Grundlegung einer operationsfähigen Dialektik I. Hamburgo, Meiner, pp. 283-306. Habermas, Jürgen. (1963), Theorie und Praxis: Sozialphilosophische Studien. Frankfurt, Suhrkamp. (1996), Between facts and norms: contributions to a discourse theory of law and democracy. Cambridge, The MIT Press.

Hart, Herbert L. A. (1981), The concept of law. Oxford, Oxford University Press.

Hauriou, Maurice. ([1933]1986), "La théorie de l'institution et de la fondation: essai de vitalisme social". In: . Aux sources du droit. Caen, Centre de Philosophie Politique et Juridique, pp. 89-128.

HenSEL, Isabell. (2009), "Grundrechtskollisionen in der Stiftungsuniversität: Überwältigte Einheit oder organisierte Vielfalt". In: Calliess, Gralf-Peter; Fischer-Lescano, Andreas; Wielsch, Dan \& Zumbansen, Peer (orgs.). Soziologische Jurisprudenz: Festschrift für Gunther Teubner zum 65. Geburtstag. Berlim, Gruyter Recht.

Herberg, Martin. (2011), "Bringing professions back in: a fresh look at the dynamics of institution-building in (world) society". In: Joerges, Christian \& FALKE, Josef (orgs.). Karl Polanyi, globalisation and the potential of law in transnational markets. Oxford, Hart, pp. 107-129.

Hoffmann-Becking, Michael. (2012), “Gibt es das Konzerninteresse?”. In: ErLe, Bernd et al. (orgs.). Festschrift für Peter Hommelhoff. Colônia, Dr. Otto Schmidt, pp. 433-446.

Kelsen, Hans. (1990), General theory of norms. Oxford, Oxford University Press.

Kennedy, Duncan. (1975), "Form and Substance in Private Law". Harvard Law Review, 89: 1685-1697.

KING, Ralph T. (1996), "Bitter pill: how a drug firm paid for university study, then undermined it". The Wall Street Journal, 12 abr., p. 6.

Ladeur, Karl-Heinz. (2006), Der Staat gegen die Gesellschaft: Zur Verteidigung der Rationalität der "Privatrechtsgesellschaft". Tübingen, Mohr Siebeck.

LANGE, Knut Werner. (1998), Das Recht der Netzwerke. Heidelberg, Fachmedien Recht und Wirtschaft.

Lautmann, Rüdiger. (1971), Soziologie vor den Toren der Jurisprudenz: Zur Kooperation der beiden Disziplinen. Stuttgart, Kohlhammer.

LAZEAR, Edward P. (2000), “Economic imperialism”. The Quarterly Journal of Economics, 115 (1): 99-146.

Luhmann, Niklas. (1990), Die Wissenschaft der Gesellschaft. Frankfurt, Suhrkamp. 
(1990), Political theory in the welfare State. Berlim, Walter de Gruyter.

. (1992a), "Some problems with reflexive law". In: Febbrajo, Alberto \& Teub-

NER, Gunther (orgs.). State, law, and economy as autopoietic systems: regulation and autonomy in a new perspective. Milão, Giuffrè, pp. 389-415.

. (1992b), "The coding of the legal system". In: Febbrajo, Alberto \& Teub-

NER, Gunther (orgs.). State, law, and economy as autopoietic systems: regulation and autonomy in a new perspective. Milão, Giuffrè, pp. 145-185.

. (2004), Law as a social system. Oxford, Oxford University Press.

Lyotard, Jean-Francois. (1987), The differend:phrases in dispute. Manchester, University of Minnesota Press.

Maunz, Theodor \& DÜRIG, Günter (orgs.). (2013), Grundgesetz: Kommentar. Munique, C. H. Beck, vol. supl. 68 .

MeAD, George Herbert. (1967), Mind, self and society from the standpoint of a social behaviorist. Chicago, University of Chicago Press.

MÖLdERs, Marc. (2012), “Kluge Kombinationen”. Zeitschrift für Rechtssoziologie, 33: 5-30.

Nonet, Philippe \& Selznick, Philip. (1978), Law and society in transition: toward responsive law. Nova York, Harper and Row.

ORTS, Eric W. (2013), Business persons: a legal theory of the firm. Oxford, Oxford University Press.

Pies, Ingo \& Leschke, Martin. (1998), Gary Beckers ökonomischer Imperialismus. Tübingen, Mohr Siebeck.

POSNER, Richard A. (1987), "The decline of law as an autonomous discipline: 19821987". Harvard Law Review, 100: 761-780.

Powell, Walter W. (1990), "Neither market nor hierarchy: network forms of organization". Research in Organizational Behavior, 12: 295-336.

Roнe, Mathias. (1998), Netzverträge: Rechtsprobleme komplexer Vertragsverbindungen. Tübingen, Mohr Siebeck.

RöHL, Klaus F. \& RöHL Hans C. (2008), Allgemeine Rechtslehre: Ein Lebrbuch. Colônia, Vahlen.

RÜTHERs, Bernd. (2004), Die unbegrenzte Auslegung: Zum Wandel der Privatrechtsordnung im Nationalsozialismus. Tübingen, Mohr Siebeck.

Savigny, Friedrich Carl von. (1840), System des heutigen römischen Rechts. Berlim, Veit, vol. 2.

Schimank, Uwe Schimank. (1996), Theorien gesellschaftlicher Differenzierung. Opladen, VS Verlag für Sozialwissenschaften.

SChluchter, Wolfgang. (1988), Religion und Lebensführung. Frankfurt, Suhrkamp, vol. 1.

Sснотт, Gisela Schott et al. (2010), "Finanzierung von Arzneimittelstudien durch 
pharmazeutische Unternehmen und die Folgen”. Deutsches Ärzteblatt International, 107 (16): 279-285 [parte 1] e pp. 295-301 [parte 2].

Song, Fujian; Hooper, Lee \& Loke, Yoon K. (2013), "Publication bias: what is it? How do we measure it? How do we avoid it?". Open Access Journal of Clinical Trials, 5: 71-81.

Song, Fujian; PArekh, Sheetal \& Hooper, Lee. (2010), "Dissemination and publication of research findings: an updated review of related biases". Health Technology Assessment, 14 (8): 1-220.

Steinhauer, Fabian. (2009), Bildregeln: Studien zum juristischen Bilderstreit. Munique, Wilhelm Fink.

Stolleis, Michael. (2009), Sozialistische Gesetzlichkeit. Staats- und Verwaltungsrechtswissenschaft in der DDR. Munique, C. H. Beck.

Stolleis, Michael \& Dunlap, Thomas. (2004), A bistory of public law in Germany 1914-1945. Oxford, Oxford University Press.

Teles, Steven M. (2008), The rise of the conservative legal movement: the battle for control of the law. Princeton, Princeton University Press.

Teubner, Gunther. (1997). "Altera pars audiatur: law in the collision of discourses". In: Rawlings, Richard (org.). Law, society and economy. Oxford, Clarendon Press, pp. 149-176.

. (2000), "Contracting worlds: invoking discourse rights in private governance regimes”. Social and Legal Studies, 9: 399-417.

. (2009), "Coincidentia oppositorum: hybrid networks beyond contract and organization”. In: Amstutz, Marc Amstutz \& Teubner, Gunther (orgs.). Contractual networks: legal issues of multilateral cooperation. Oxford, Hart Publishing, pp. 3-30. . (2011), Networks as connected contracts. Oxford, Hart.

. (2013), “'And if I by Beelzebub cast out Devils, ...: An essay on the diabolics of network failure". In: Grundmann, Stefan; Cafaggi, Fabrizio \& Vettori, Giuseppe (orgs.). The organizational contract: from exchange to long-term network cooperation in european contract law. Londres, Ashgate, pp. 113-135.

. (2014), "Exogenous self-binding: how social systems externalise their foundational paradox". In: Corsi, Giancarlo \& FeBbrajo, Alberto (orgs.). Transconstitutionalism. Farnham, Ashgate.

Thornhill, Chris. (2013), "A sociology of constituent power: the political code of transnational societal constitutions". Indiana Journal of Global Legal Studies, 20: 551-603.

VARELA, Francisco J. (1992), "Whence perceptual meaning? A cartography of current ideas". In: VARELA, Francisco J. \& DupuY, Jean-Pierre (orgs.). Understanding origins: contemporary views on the origin of life, mind and society. Dordrecht, Springer. 
Vesting, Thomas. (2007), Rechtstheorie: ein Studienbuch. Munique, C. H. Beck.

Weber, Max. (1968), Gesammelte Aufsätze zur Wissenschaftslehre. Tübingen, Mohr Siebeck.

Weinberg, Alvin M. (1972), "Science and trans-science". Minerva, 10: 209-222.

Weitzenboeck Emily M. (2012), A legal framework for emerging business models: dynamic networks as collaborative contracts. Cheltenham, Edward Elgar.

WEYER, Johannes. (2011), Soziale Netzwerke: Konzepte und Methoden der sozialwissenschaftlichen Netzwerkforschung. Munique, Oldenbourg.

Welsch, Wolfgang. (1996), Vernunft: die zeitgenössische Vernunftkritik und das Konzept der transversalen Vernunft. Frankfurt, Suhrkamp.

WIEACKER, Franz. (1996), A history of private law in Europe: with particular reference to Germany. Cambridge, Oxford University Press.

Wielsch, Dan. (2008), Zugangsregeln: Die Rechtsverfassung der Wissensteilung. Tübingen, Mohr Siebeck.

. (2009), "Die epistemische Analyse des Rechts: Von der ökonomischen zur ökologischen Rationalität in der Rechtswissenschaft”. Juristenzeitung, 2: 67-77.

Wiethölter, Rudolf. (1968), Rechtswissenschaft. Frankfurt, Fischer.

. (1995), "Zur Argumentation im Recht: Entscheidungsfolgen als Rechtsgründe?”. In: TeUBner, Gunther (org.). Entscheidungsfolgen als Rechtsgründe: Folgenorientiertes Argumentieren in rechtsvergleichender Sicht. Baden-Baden, Nomos, pp. 89-120.

Williamson, Oliver E. (1985), The economic institutions of capitalism: firms, markets, relational contracting. Nova York, Free Press.

. (1991), "Comparative economic organization: the analysis of discrete structural alternatives". Administrative Science Quarterly, 36: 269-296.

ZöLlnER, Wolfgang. (1996), "Regelungsspielräume im Schuldvertragsrecht: Bemerkungen zur Grundrechtsanwendung im Privatrecht und zu den sogenannten Ungleichgewichtslagen”. Archiv für die civilistische Praxis, 196. 


\section{Resumo}

\section{Direito e teoria social: três problemas}

Três desastres da teoria são a razão de a doutrina jurídica que, particularmente na Alemanha no início do século Xx, havia desenvolvido uma estreita simbiose de direito e teoria social ter imunizado a si mesma contra a influência desta última. A alternativa para essa autoimunização é uma abordagem distanciada, segundo a qual o direito não toma teorias sociais em seu valor nominal, mas gera, em um complexo processo de tradução, valor agregado à doutrina jurídica. $\mathrm{O}$ artigo lida com três problemas na relação entre direito e teoria social. Primeiro, a concorrência entre as teorias: como o direito deve fazer uma seleção se teorias sociais concorrentes dão origem a análises mutuamente incompatíveis de fenômenos sociais? Em seguida, a transferência de conhecimento: os resultados das teorias sociais podem ser aplicados diretamente no âmbito do direito? As teorias sociais podem orientar a seleção das regras e sanções legais? Por fim, há a questão extremamente difícil da normatividade das teorias sociais: critérios normativos para a prática jurídica podem ser derivados de teorias sociais? O artigo usa como exemplo o problema dos efeitos horizontais de direitos constitucionais em redes semiprivadas de pesquisa médica.

Palavras-chave: Direito e teoria social; Jurisprudência sociológica; Catástrofe da teoria; Transferência de conhecimento; Normatividade; Viés de publicação.

\section{Abstract}

Law and social theory: three problems

Three theory disasters are the reason why legal doctrine which, particularly in Germany in the early 20th century, had developed a close symbiosis of law and social theory, has immunized itself against the influence of social theory. The alternative to this self-immunization is a distanced approach, whereby the law does not take social theories at their nominal value, but in a complex process of translation generates added value to legal doctrine. The article deals with three problems in the relation between law and social theory. First, competition between theories: how is the law supposed to make a selection if competing social theories give rise to mutually incompatible analyses of social phenomena? Then, knowledge transfer: can the results of social theories be directly applied within the law? Can social theories guide the selection of legal rules and sanctions? Finally, there is the extremely difficult question of the normativity of social theories: can normative criteria for legal practice be derived from social theories? The article uses as an example the problem of horizontal effects of constitutional rights in semi-private networks of medical research. Keywords: Law and social theory; Sociological jurisprudence; Theory catastrophe; Knowledge transfer; Normativity; Publication bias.
Texto enviado em 19/5/2015 e aprovado em 24/6/2015. DOI: http://dx.doi.org/10.1590 /0103-2070201524.

Gunther Teubner foi professor da cadeira "Otto Kahn-Freund" na London School of Economics. Atualmente, é investigador principal do polo de excelência "Normative Orders", na Universidade Johann Wolfgang Goethe de Frankfurt. Suas áreas de pesquisa são teoria social do direito, teoria do direto privado, direito contratual e direito comparativo. É autor de Transnational societal constitutionalism (2013); Constitutional fragments: societal constitutionalism in the globalization (Oxford, Oxford University Press, 2012); Networks as connected contracts (Oxford, Hart, 2011); Contractual networks (Oxford, Hart, 2008). E-mail: g.teubner@jur.uni-frankfurt.de. 